\title{
Exam Papers On-Demand
}

\author{
Sally Rumsey and Jon Maslin
}

\section{The authors}

Sally Rumsey is Academic Liaison Librarian (Human Sciences and Education) and acted as Research Assistant on the Exam Papers Project. She has previously worked on the Tolimac (Total Library Management Concept) Project (http://tolimac.ulb.ac.be/) (in association with Université Libres de Bruxelles and others) and evaluation of the Patron (Performing Arts Teaching On-line) system (http://www.lib.surrey.ac.uk/patron2/).

Jon Maslin is Manager of Learning Systems (Centre for Learning Developments). He has been responsible for the development and implementation of a range of electronic information projects that have included advanced editorial, production and delivery services. Latterly he was project manager for the Patron project that integrated multiple media resources in a library and teaching environment.

\section{Email: $\underline{\text { S.Rumsey@surrey.ac.uk }}$}

\section{The occasion}

The authors were the winners of the Daphne Clarke Research Prize for Practitioners 2001

\begin{abstract}
The Exam Papers On-demand Project comprised 1) research into the feasibility of electronic provision of University of Surrey past exam papers and 2) the subsequent development of a scalable and sustainable system for allowing Internet access to past exam papers by members of the University. Although this has been achieved at other institutions, the solution at the University of Surrey is believed to be innovative in a number of ways. The achievements include the compliance with the Dublin Core metadata standard and the design of a generic system that could be used in the future for additional learning and teaching resources.
\end{abstract}

\section{Background}

The University Library (hereafter referred to as the Library) is the holding centre for copies of University past exam papers. There were a number of problems associated with this practice that the Library was keen to rectify. This project was initiated to address these issues and investigate the feasibility of a web-based document management solution.

\section{Current Document Management Problems at the University of Surrey}

The problems associated with the storage and access to exam papers in the Library included:

- $\quad$ papers were issued on 3 hour loan for Library use only

- papers were only accessible to those visiting the library; 
- there were a limited number of copies and during busy exam periods demand far outstripped supply;

- the above caused difficulties for part-time, open and distance learners ;

- occasional vandalism of the bound copies lead to incomplete papers as these were not replaced by the Examination Office;

- bound volumes were incomplete;

- papers were bound into volumes by faculty/school - a volume issued to one reader may prevent access for a reader from a different department;

- there was a publication delay of about 3-6 months;

- intensive in staff time as all exam volumes have to be checked for accuracy against detailed contents lists.

\section{Aims and Objectives of the Project ${ }^{1}$}

This project was designed to examine the existing situation with past exam papers at the University of Surrey (UniS), assess the feasibility of providing on-demand access to papers and, if it was deemed feasible, to design and create a pilot system which was to be evaluated. The project was divided into two distinct sections. Phase 2 was dependent on the outcome of Phase 1:

- Phase 1: Analysis of the needs of the University community, feasibility study and recommendations for the specifications of the proposed system (Sept 1999 - Jan 2000)

- Phase 2: Implementation and evaluation of the pilot service (Jan 2000 - Dec 2000)

The objectives of the project were to:

- gain the co-operation of and collaboration and participation with Registry;

- assess the feasibility of providing online access to University of Surrey past exam papers;

- examine the current situation concerning any existing document management systems in use at the University of Surrey;

- analyse University requirements (system and functionality) of a web based system for accessing exam papers ;

- to evaluate the benefits of digital versions of exam papers to UniS students and staff;

- to design and create a scaleable and sustainable system for the provision of exam papers on demand;

- to evaluate the pilot system (both the user interface and the administrator's role);

- to offer recommendations as to how the system may be incorporated into mainstream Library services.

\footnotetext{
${ }^{1}$ The original proposal for this project had included a means of on-demand access to UniS theses. Phase 1 concluded that although this was possible, it was not feasible in the short term to include theses and that the project should concentrate on the more pressing and feasible issue of making the exam papers available via the Internet. A small number of theses will be included in the Phase 2 Part 2 in order to test the practical issues involved with creating this service.
} 


\section{Funding}

Funding was provided by the Fund for the Strategic Development of Learning \& Teaching (FSDLT). This was an internal University fund managed by the Steering group of the Committee for the Development of Learning \& Teaching.

\section{Staffing and Responsibilities}

The Research Assistant and technical team reported to the Head of Research and Learning Support Systems until October 2000. The Research Assistant was an existing member of Library staff who was recruited for the period of the project. From October 2000 they reported to the Library Information Systems Development Officer. All technical expertise was provided by the LSU (Learning Systems Unit).

\section{Methods}

\section{Phase 1}

In order to ascertain whether or not digitisation of exam papers was feasible it was necessary to gather information from key figures at the University and investigate technical details of the proposed system. Information was obtained regarding similar established and pilot systems at other institutions to aid the analysis. Methods of investigation included interviews, both semi-structured and unstructured, questionnaires, demonstrations and desk research. The reason for choosing these methods was to acquire enough information to satisfy the aims and objectives of the project.

Elements of the research comprised:

1. Interviews with:

- the University Examinations Officer in Registry;

- one or more representatives from each of the twelve Academic Schools;

- appropriate Library staff;

- other key staff in the University (TLSU (Teaching \& Learning Support Unit) and ORCAM (Office of Recruitment, Communications and Marketing) for their technical expertise);

- the University Computing Services Manager.

2. Questionnaires and questions were posed to:

- the University's solicitors for copyright issues

- end users

3. Demonstrations of:

- AIMS (Academic Information Management System) an electronic document management system (EDMS) developed at Southampton University

- the EDMS used in SEMS (Surrey European Management School)

4. Investigations into systems in use at other institutions

It was first necessary to discover whether or not other institutions provided on-demand Internet access to exam papers. This was achieved by searching the Internet and by questioning Library staff. 
Three methods of investigating the systems in use at other institutions were used.

- Investigation using the Internet (it was usually not possible to access the exam papers due to authentication restrictions)

- Telephone interviews or e-mail questionnaires were performed with the creators or administrators of systems at Birmingham University, South Bank University (SBU), Edinburgh University, University College London (UCL) and Farnborough College of Technology (an institution affiliated to UniS)

- A request for information placed on the SCONUL (Standing Committee Of National and University Libraries) discussion list during November 1999. The members of this list are Chief Librarians and Directors of Information Services.

These investigations provided information to aid the decision as to whether UniS should provide access to exam papers on-demand. They also provided information concerning the hardware and software used in other institutions for this purpose.

5. In order to satisfy the question of feasibility investigations had to be undertaken into:

- methods of storage of data;

- the format of submitted material;

- methods of authentication of users;

- the likely workload that would result from the proposed system .

Further information was obtained from the Internet and manufacturers' brochures and publicity material

\section{Issues covered during the research}

The University Examinations Officer in Registry stated that Registry had no interest in the exam papers "after the event."

Representatives from each of the twelve Academic Schools were asked questions concerning

- the content of the papers;

- whether the School had an existing EDMS;

- existing practice with exam papers;

- expected numbers of papers;

- the maintenance and management of the proposed system;

- on-demand system requirements and functionality;

- access to material and user authentication;

- the quality required;

- whether the School would be willing to collaborate.

It became clear that Schools wanted the papers to appear in a format as close to the printed version as possible. They also wanted the system to be made available to members of the University only. Most Schools were willing to commit themselves to taking part in the project at this early stage. Only one School had an existing EDMS that was too large and expensive a system for the Library to adopt. 
Library staff were asked similar questions to the Schools but had more input concerning the management of the system. They influenced the choice of quantities of papers and the management of technical support.

The TLSU (Teaching \& Learning Support Unit) the University Computing Services Manager advised that an EDMS would not be suitable for the Library's purpose. The response from the University's solicitors on copyright issues led the Library to the conclusion that Schools had to take the responsibility for copyright material. The end users survey was brief and too small to be conclusive, however, it was apparent that the small numbers of students questioned were keen for the papers to be made available online. The AIMS System staff at Southampton University would not provide any backup for their EDMS and it was decided that their system was not suitable for the Library's purpose.

Investigations into systems in use at other institutions confirmed that scanning was to be avoided if at all possible and that PDF would be a popular choice of format.

Comparisons of methods of storage of data were undertaken. Estimates of the amount of expected data were calculated and then different methods of storage compared. This included the issues of backup and archiving. It quickly became clear that material should only be accepted in electronic format with scanning an option only in extreme cases. The workload that would result from the proposed system was estimated including the time for optical character recognition and proof reading. These calculations confirmed that scanning was not a practical option.

There were problems with the methods of authentication of users but collaboration with the University's Computing Services resulted in the problems being solved.

\section{Outcomes of Phase 1}

Phase 1 concluded by recommending that:

- it was feasible to supply access to past exam papers using an on-demand web-based system;

- during the pilot digitised items should be mounted on the library web pages;

- exam papers from 1998, 1999 and 2000 should be included in the pilot;

- only a small number of theses should be included in the pilot to test the system;

- items should only be available to members of the University. ;

- users should be permitted to read and print, but not download exam papers;

- the design and specification of the system is documented and agreed by all concerned;

- technical support is discussed at the outset;

- material should be submitted to a specified directory via FTP or other acceptable means in an agreed format (to be specified);

- access should be authenticated by user ID and password;

- users should have to click on a copyright declaration to indicate acceptance of the terms and conditions of use. 


\section{Transfer to Phase 2}

Phase 1 of the exam papers and theses project (Analysis, Specification and Feasibility) was completed in January 2000. A report of the findings was distributed to all academic schools and other key people in the University. The funding committee of the FSDLT agreed that the project should proceed to Phase 2 (Implementation and Evaluation). Phase 2 was to be completed by the end of December 2000. Phase 2 was divided into two parts:

- Part 1 - creation of a pilot service in collaboration with 5 academic schools (alpha testing)

- Part 2 - setting up of the full service with the remaining schools including submission of details of papers by administrative staff in the Schools (beta testing)

The Mathematics Department and SEMS (Surrey European Management School) were already mounting their exam papers on the web so it was agreed to create links to their site from the library web pages. The Maths papers were in Postscript format and the Department was planning to convert them to PDF to make access easier for students. The Library converted the papers that the Department sent for inclusion in the pilot to PDF. The Library offered to convert the remaining papers for Maths as a service in return for the Department mounting these converted papers on to their website.

The Library will use papers from the School of Performing Arts to test the link to Patron (Performing Arts Teaching Resources Online) for viewing scores. This will enable students to view scores that have been copyright cleared.

\section{Technical description of the resulting pilot system}

The system consisted of three parts:

- The administrator's interface where details of the papers are added by the Schools and the file containing the paper is sent to the Library;

- The LSU processes - to include conversion to PDF, scanning, checking;

- The end-user interface - where users access the papers via an Internet browser.

\section{Adminstrator's Interface}

This interface consisted of a web-based form for the administrator to complete with details of each exam paper (see example below). The use of drop-down menus meant that the amount of typing necessary was minimal and ensured consistency of naming (and therefore indexing). This form created the data necessary for display on the index of the end-user interface. 


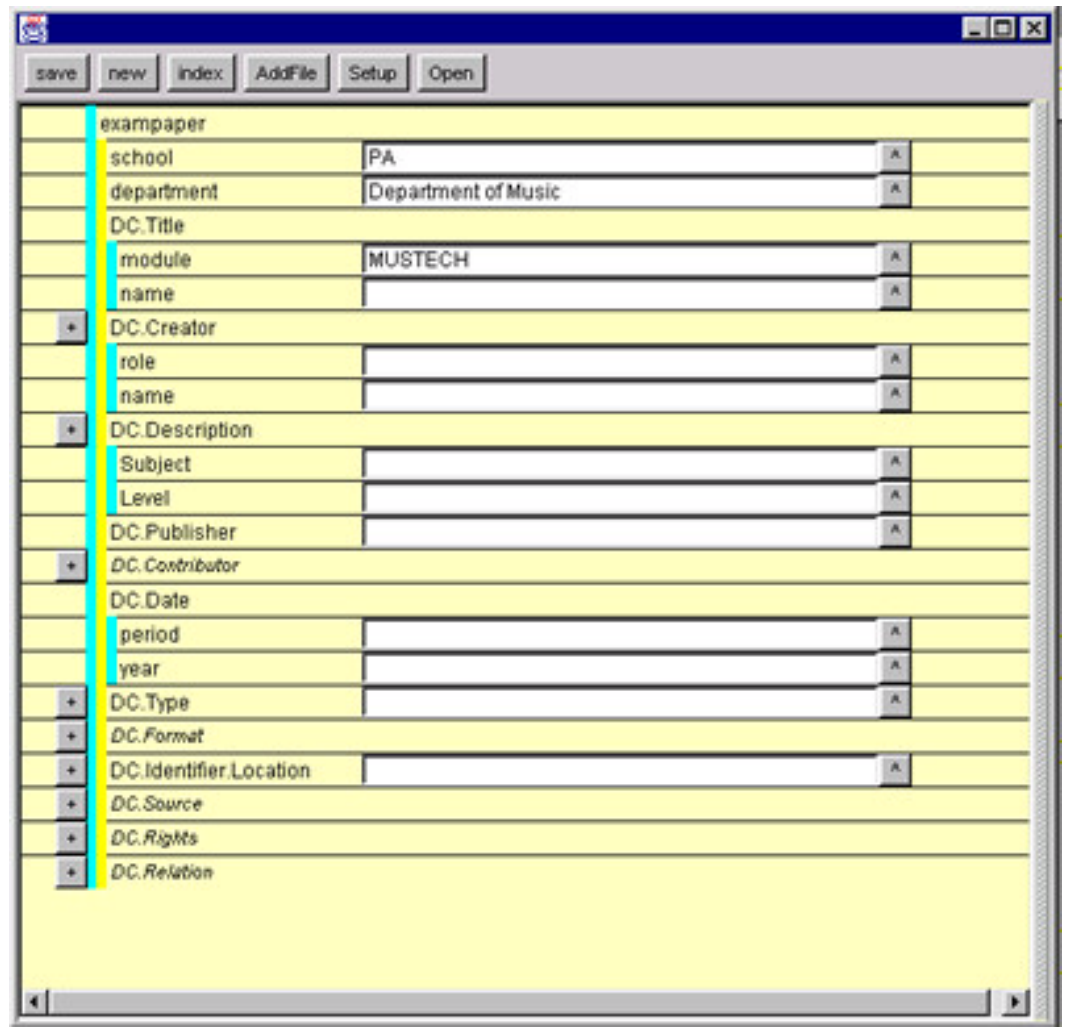

The form was created using an XML schema and standard Dublin Core metadata plus extensions for improved search and retrieval. The form can be edited as necessary.

The administrator attaches the file containing the exam paper to the form and submits this to the Library. The correct details are then attached to each paper. The Library will inform the administrator via e-mail that the paper has been received. Content of the papers will be the responsibility of the Schools. The web pages will include a disclaimer by the Library concerning any copyright material that the Schools may have included in the papers. The Library will not access any files. If there are any problems (for example, formatting) that appear in the web versions, the school should inform the Library who will work together with the School to remove any errors.

\section{LSU Processes}

There may be instances where Schools have to supply the Library with printed copy. The LSU will scan such items for inclusion in the system. The LSU will create any additional links such as those to Patron. Some schools will be able to supply the Library with papers already in PDF. The LSU will convert papers for those schools who are not able to do this for themselves. ${ }^{2}$

\footnotetext{
${ }^{2}$ At the end of the project Adobe Acrobat Writer was purchased and installed on computers in Schools where staff were sending papers for addition to the system. This allowed conversion to PDF to take place in the School before sending the papers to the Library. It was paid for by the project.
} 


\section{End-user Interface}

The end-user interface is available via the Library web pages under the electronic resources button. The web page address is: http://www.surrey.ac.uk/Library/papers

End-users are presented with a tree structure allowing them to select papers by school, department, course, level, year and paper title (see example below). This has been modified to allow users to toggle between course and module name/number and therefore have more flexibility in selection and retrieval.

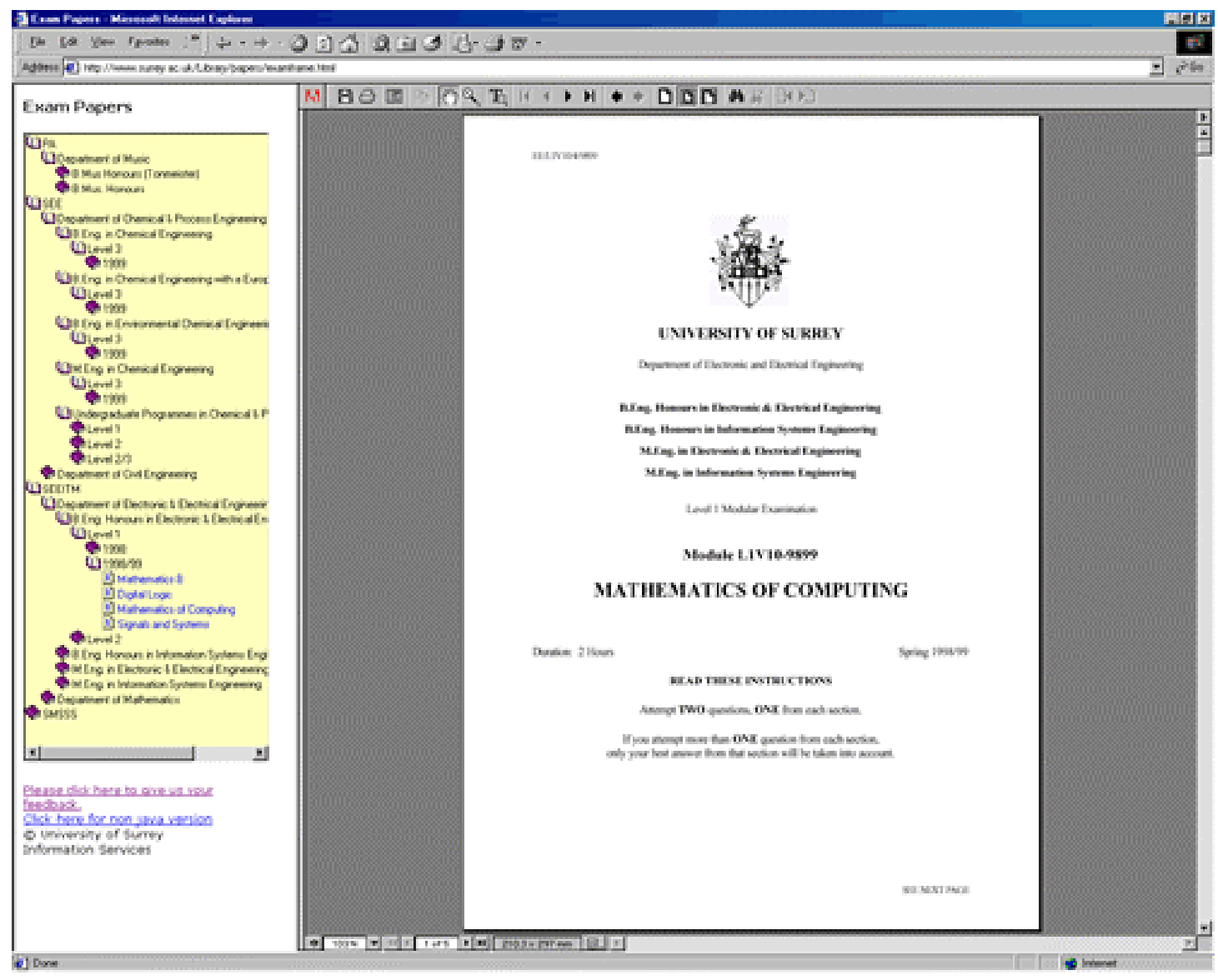

\section{Other technical issues}

\section{Authentication}

The pilot system was only available on campus and was authenticated by IP address. The full service has been opened up to University members off campus using username and password access. 


\section{Storage of data}

Data is stored on the Library LSU server. This is a temporary measure. As more papers are added the Library will require more storage space. This issue will be raised with Library management over the coming year.

\section{IE/Netscape Navigator}

The system is designed to work neatly using Internet Explorer where Acrobat launches in the blank space next to the index. Use of Netscape Navigator causes Acrobat to launch in a separate window.

\section{Non-Java Version}

After some problems on some computers there is now a non-Java version which should work on all machines.

\section{Watermarking}

Some schools professed an interest in watermarking items a) to ensure the user that the paper is genuine and b) to discourage copyright infringement. Some test papers were created with electronic watermarks. These will be distributed to the schools for consultation and, if the school wishes, watermarks can be included in their papers.

\section{Management and administration of the pilot system}

It was decided that it would be preferable for the papers in the pilot system to be inputted by the research team. The reasons for this were:

- to check the software and procedures

- to enable the correction of any errors in the software/procedures

- to take timings for the purposes of estimates of workload and costs

- to aid the writing of instructions for future users

Schools sent papers to the Library during Part 2 via the administrator's interface.

\section{Evaluation of the Pilot Service}

The front-end interface was evaluated by end users (students and academic staff). The evaluation was informal ie no use was made of targetted populations calculated from the total numbers of students and staffs and their subject areas. Two questionnaires/feedback forms were designed, one for students and the other for academic staff. They were constructed to be short and simple i) because the students were in the midst of exams and it was therefore felt they would not complete a lengthy questionnaire and ii) because the academic staff were believed to be under the pressures of everyday work. An added incentive of entry to a prize draw was offered to those students who completed the questionnaire. The evaluation served the purposes of:

- giving users the opportunity to state their views (especially in the qualitative questions)

- publicising the papers

- pinpointing technical errors or problems with the system 
Students were able to find the questionnaire on the exam papers web site. It was displayed as a web form and involved checking boxes and typing in comments. The form was then e-mailed to the Research Assistant by means of a "Submit" button. The Academics were sent their questionnaire as an e-mail message.

The student respondents remained anonymous (they were required to give their e-mail address for entry to the draw) but indicated to which Academic school they belonged. The students' questions were designed to elicit the following information:

- to rate the service (for ease and speed of use and quality of the images)

- to compare the electronic service to current printed exam paper provision

- to identify what they liked and what they would change about the service

- to ascertain whether or not users had experienced problems accessing papers

- to discover how they had found out about the service

The academic staff questionnaire was designed to provide answers to the following:

- The School to which they belonged

- To rate the service (for ease and speed of use and quality of the images)

- Usefulness to their students

- To identify what they liked and what they would change about the service

- To find out whether or not users had experienced technical problems

- To indicate whether they were prepared to promote the service to students

The questionnaires were piloted before the evaluation.

Students were made aware of the new service via, posters and flyers in strategic positions around campus, E-mail, publicity on the Library web pages and Bare Facts (student newspaper).

Academic staff were made aware of the papers via e-mail. The message also contained the evaluation questions.

60 students submitted replied to the questionnaire. (The total student population is approximately 9,000, however this was an informal evaluation). Users overwhelmingly found the papers web site easy to find and most (35 users) rated the speed of finding the paper they required as "good" or "excellent." Users liked the quality of the papers on screen (41 rated it "good" or "excellent") and most users found it easy to print out papers (30 respondents). The total number of poor ratings from all questions was just 39, compared to 204 responses that rated the service as "good or "excellent."

The main comment that came from users concerning any changes they would like to see made to the service was the addition of more papers.

Eight completed questionnaires were received from academic staff, seven returned student feedback forms and five comments were received via e-mail (a total of 20). Half the Academic staff liked the speed of finding the papers (10 responded with "good" or "excellent") and the ease of navigation (11 "good" or "excellent") but they were not so satisfied with the quality on screen (only 7 rating it as "good" or "excellent"). There was, 
however, a positive response to the quality of the printed papers and they were unanimous in their willingness to promote the service to their students and in not encountering any problems accessing the papers. There were requests for the module codes to appear in the index and also for grouping of papers into subjects, rather than years. Some staff were keen for exam solutions to be included and this is currently being investigated.

Overall, response to the pilot system was positive. The main criticism was that not enough papers were included. Responses allowed the technical team to be alerted to problems such as the access problems encountered in the Department of Electronic \& Electrical Engineering computing labs and those encountered when accessing SMSSS (School of Management Studies for the Service Sector) papers. These were quickly solved.

Many respondents gave suggestions for modifications that they would like, some of which were incorporated over the coming months. Users liked the convenience of the system and preferred printing out papers to using the photocopiers in the Library.

\section{Phase 2 Part 2}

\section{Instructions/Guidelines for exam paper creators}

In order to reduce the number of formatting problems in the PDF version of the papers there are a number of features of MS Word that must be used in a particular way, for example, the use of standard paragraphs rather than the tab function. The Library has issued guidelines for those that create exam papers so that the papers appear in the correct format without the need for editing.

\section{Training for Administrators}

Schools were asked to supply two named contacts who will be responsible for inputting the details of papers. Training and help was offered these inputters and representatives from most schools came to the Library for training. The Library is willing to help in any way it can to enable the system to become an accepted feature of the University's resources.

\section{Hotlink to Talis catalogue}

A link will be created from the Library catalogue directly to the papers to make access for users easier. This work is still in progress as papers are added.

\section{Fault reporting and difficulties}

The service includes a help facility by which the users (both students and staff) can request help in times of difficulty. 


\section{Addressing Institutional and Users Needs}

\section{Relationship with the University Mission and School plans}

The University has clearly demonstrated its commitment to support teaching and learning through its Vision Statement and through the Learning and Teaching Policy Statement. Objective Two in this latter document proposes "that teaching and learning methodologies and assessment strategies are varied and appropriate to the learning objectives of the programme and to the needs of the learner". The Library's Mission Statement is "to meet the information needs of the University for teaching, research and administration". The varied R\&D activities e.g. DiLIS (Distance Learning Library and Information Service), PATRON (Performing Arts Teaching On-line) and of other sections of Information Services such as the TLSU (Teaching \& Learning Support Unit), clearly demonstrate our proactive support of these goals. This project provides another example of how the Library is seeking to deliver materials directly to the student both on campus and beyond, in a timely and accessible manner to facilitate the Learning and Teaching objective described above.

\section{How the system answers the needs of the users}

\section{Addressing the student's problems}

This system will address all the problems of access to past exam papers for students, especially those who are part-time, off campus or distance learners. There will be no change in provision for those students in SEMS as they already had access to exam papers on-demand. The Maths students will benefit because, even though they already had access to exam papers via the Internet, the service was only available in Postscript format. In implementing the new system the Library converted the Maths papers to PDF so making the papers more accessible to students. This is because Adobe Acrobat Reader can be downloaded free of charge and is a widely used cross-platform format.

The design of the system means that it should be easier for users to find copies of the papers they require.

The results from the evaluation exercise showed that the students thought the new system was beneficial (ie more convenient, cheaper and quicker than the current provision of papers) and that they would like more papers to be added. Staff reported that they thought the system would benefit their students.

\section{The benefits to Academic Schools}

The benefit that the academic schools will reap from the system is dependent on the current system in each School. For those few Departments where papers are not available to students in the School and students are directed to the Library for access there will be an increase in workload for administrative staff. This is because they will have to spend time inputting papers into the system whereas exam papers had not generated any workload previously. However, for those that provide copies of papers and are forced to sort, duplicate and administer a filing system there will be a time saving for staff. Those departments will also save space used for storage. 
It has been shown, particularly by the experience of the Maths department, how the system benefits an academic department during a TQA (Teaching Quality Assessment). Any drawbacks that concern the schools will be counterbalanced by the benefits when undergoing a TQA. It will be the responsibility of the Library to make schools aware of these benefits.

The papers being easily accessible should result in more satisfied students. This can only be an advantage to the schools. In the past students have complained at course board meetings (formal School/Departmental meetings that are minuted) that papers were not readily accessible. This system will address those concerns.

Academic Staff were in favour of the new system. There are some areas where minor changes were recommended such as the categories to which papers were assigned and the labelling of those categories.

The generic nature of the system means that in the future other Learning \& Teaching resources such as course notes will be able to be included in the system. The web-based design of the system allows for the inclusion of multimedia and live web links in stored items.

\section{The problems faced by the Library}

Adoption of the electronic system will mean that the Library will no longer have to hold printed versions of the papers. This will save space, but not until there is at least three years worth archive of papers. Retrospective digitisation would be too large a task for the library to undertake so it would have to keep the current printed versions of papers.

Problems of vandalism and incomplete copies will be solved by the system, as will the difficulty of finding the required paper by users. The Library would be able to supply all the users that require the items simultaneously and the problems at busy periods would cease therefore increasing access.

The implications on staff workload are as yet unclear. Although some tasks will disappear (for example, shelf tidying, searching for items and processing of hard copies) there will be tasks such as scanning and conversion to PDF that will need attending to. It will be necessary to provide computer systems support for electronic provision of materials: in this case this will be provided by the LSU rather than the library "front line" staff that deal with printed copies. The work is therefore moving from one group of staff to another.

\section{Implications for the University}

Use of a generic system that can deal with many types of electronic items will improve access to learning and teaching resources. In addition to exam papers it will allow staff to include live web links and, where practical, multimedia sections within items. This will be attractive to students and perhaps serve to attract more students to UniS having the effect of increasing the University's income. 
Better accessibility to resources could have the effect of higher scores at Subject Review. The results of Subject Reviews are in the public domain and play a part in university "league tables." Better scores mean more positive publicity for the university. This may have a direct effect on applications.

Use of Dublin Core is innovative (as far as can be ascertained) and will have the effect of raising the University's profile providing the system is publicised. It also means that if items such as theses are included for open access, retrieval of these items will be more reliable for users.

\section{Achievements}

- Simple and efficient method of delivery of electronic exam papers

- Conforms to Dublin Core metadata standards (for more information see the Dublin Core site at http://purl.org/DC/)

- A generic system that can be used for other learning and teaching materials

- The system developed has created a generic forms builder from the XML metadata schema.

- Use of Adobe Acrobat to view papers

- Ability to watermark papers if required by Schools

- A non Java version for those who require it

- Links to the Patron (Performing Arts Teaching Online) system (http://www.lib.surrey.ac.uk/PATRON2/)

- Makes papers available to multiple users 24 hours per day from any site with Internet access on or off campus

\section{Exit strategy to a mainstream service}

The full service was made available from January 2001. Discussion is still underway to determine how it will be absorbed into mainstream Library services. An estimation of costs and workload was carried out prior to handover.

University of Surrey Exam Papers Online can be found at http://www.surrey.ac.uk/LS/exams/

A demonstration is available at this URL for non-members of the University. 